\title{
Double burden: a cross-sectional survey assessing factors associated with underweight and overweight status in Danang, Vietnam
}

Kiet A Ly ${ }^{1 *+}$, Thanh GN Ton ${ }^{2+}$, Quang $V \mathrm{Ngo}^{3}$, Tung $T \mathrm{Vo}^{3}$ and Annette L Fitzpatrick ${ }^{4}$

\begin{abstract}
Background: Many low- to middle-income countries are faced with an increasing prevalence of overweight/ obesity while that for underweight remains high, a duality termed "double burden"; both are key risk factors for chronic diseases. This cross-sectional study assesses the prevalence and factors for underweight and overweight/ obesity among adults in Danang, Vietnam, using WHO standard and suggested Asian-specific BMI cut-offs.

Methods: In 2010, 1713 residents age $\geq 35$ years from 900 households in 6 of 56 urban, rural and mixed urban-rural communes in Danang were selected using multistage-cluster sampling methodology to participate; 1621 qualified adults enrolled. Participants completed a health survey based on WHO STEPwise Approach to Chronic Disease Risk Factor Surveillance and additional questions on chest pain and stroke symptoms. Anthropometric and other measurements were conducted. Relative risk regression was used to identify independent risk factors for underweight or overweight/obesity according to WHO standard cut-offs and suggested Asian-specific cut-offs $\left(<18.5 \mathrm{~kg} / \mathrm{m}^{2}\right.$ or $23-27.49 \mathrm{~kg} / \mathrm{m}^{2}$; and $\left.\geq 27.5 \mathrm{~kg} / \mathrm{m}^{2}\right)$.

Results: We observed $12.4 \%$ prevalence of underweight and $16.0 \%$ for overweight/obesity using WHO standard. The prevalence of overweight/obesity doubled (33.7\%) when Asian-specific cut-offs were applied. For both definitions, rural communes had the highest prevalence of underweight while urban communes had the highest prevalence of overweight/obesity. Being underweight was associated with less urbanization. Factors independently associated with being underweight included older age, rural living, current smoking, and lower systolic pressure. Factors independently associated with Asian-specific BMI definition for being overweight/obese included older age, urbanization, higher systolic pressure, and diabetes. Age was not an independent factor with WHO standard cut-offs; however, myocarial infarction and diabetes showed strong associations.

Conclusions: The double burden of underweight and overweight/obesity observed in Danang is consistent with patterns found for large cities in Vietnam that are undergoing rapid economic growth and urbanization of lifestyle. Factors independently associated with underweight and overweight/obesity status by WHO standard and Asian-specific definitions include urbanization and modifiable lifestyle factors. Further studies are needed to define ethnic specific BMI cut-offs for Vietnam and to explore strategies to reduce the rising prevalence of overweight/ obesity.
\end{abstract}

\footnotetext{
* Correspondence: kietaly@uw.edu

${ }^{\dagger}$ Equal contributors

'Department of Oral Health Sciences, School of Dentistry, University of

Washington, Seattle, WA, USA

Full list of author information is available at the end of the article
} 


\section{Background}

Overweight and obesity are recognized as global public health problems because they are associated with increased risk of many diseases including hypertension, type 2 diabetes, cardiovascular diseases, stroke, osteoarthritis, and some cancers [1,2]. Similarly, underweight is a risk factor for many chronic diseases such as respiratory illnesses, osteoporosis, as well as diabetes, hypertension, and cardiovascular diseases [3-5]. With continuing economic growth over the last two decades, many lowto-middle income countries in Asia are facing increasing prevalence of overweight/obesity while underweight remains a public health challenge. The dual burden of underweight and overweight/obesity has been termed the "double burden" of diseases [6], and has received considerable attention in Asia $[3,5,7,8]$ where rapid economic growth and development, urbanization, and associated change in dietary and lifestyle patterns are fueling the rapid rise of overweight/obesity and dietrelated diseases.

The World Health Organization's (WHO) "standard" definition for underweight, overweight, and obesity by body mass index (BMI) are $\leq 18.5 \mathrm{~kg} / \mathrm{m}^{2}, 25$ to $<30 \mathrm{~kg} / \mathrm{m}^{2}$, and $\geq 30 \mathrm{~kg} / \mathrm{m}^{2}$, respectively [9]. However, Asian populations appear to have greater cardiovascular risk, higher morbidity and all-cause mortality than western populations at any given BMI level [10].

Currently debated is whether the standard WHO BMI cut-off points for overweight and obesity are appropriate for use across racial and ethnic groups, particularly among Asians. Differences in lifestyle factors, limbs, trunk, and stature proportionality, and in ethnic variations of body fat distribution in relation to BMI have been debated [11]. Similarly, waist circumference, another indicator for overweight and obesity, is also facing debate regarding appropriate cut-off points for different racial ethnic groups. In a large prospective study with 5,515 Europid and 2,214 ethnically South Asians, Cameron and collegues [12] found that using the current recommended waist circumference cut-offs, South Asian men and women had significantly higher estimated incidence of diabetes $(5.8 \%$ and $2.1 \%$, respecitively) compared to their Europid counterparts $(0.6 \%$ and $0.4 \%$, respectively). Studies attempting to define waist circumference cut-offs as related to ethnic Asians are numerous [13-17] and growing. The WHO Expert Consultation Report of 2004 acknowledged the existence of greater risk at lower BMI for Asians and that Asian-specific BMI cut-off points for better assessment of risk-related diseases may be needed. The panel suggested retaining the standard WHO BMI cut-offs as the international classification but identified further "potential public health action points" at 23.0, 27.5, 32.5, and $37.5 \mathrm{~kg} / \mathrm{m}^{2}$ along the continuum of BMI [18].
Numerous studies conducted among various Asian ethnic groups have attempted to justify lower BMI cut-offs for assessing overweight-related disorders and for evaluating obesity-related morbidities and mortalities [10]. While further work is needed to define the appropriate Asian- or ethnic Asian-specific BMI cut-off points, what is clear is the existence of the "double burden" of underweight and overweight/obesity and their associated increased morbidity and mortalities in low- and middle- income countries. In Vietnam, Ha and colleagues compared National nutrition data collected in 2000 and 2005 and reported that Vietnam was experiencing this double burden with a trend towards decreasing underweight and increasing overweight/obesity over the two time points [19]. Other studies conducted in major economic regions in northern and southern Vietnam reported even greater prevalence of overweight and obesity compared to national findings [5,20,21]. Danang City is a major economic hub in central Vietnam and, to date, a study evalutating weight status of its population has not been reported.

Our goals were to (1) estimate the prevalence of underweight and overweight/obesity in a populationbased sample of adults age 35 years and older living in Danang City; (2) identify independent factors associated with being underweight and overweight/obese by two definitions, the standard $\mathrm{WHO}$ and the WHO suggested Asian-specific BMI cut-off points; and (3) compare our findings with those previously reported for Vietnam.

\section{Methods}

\section{Setting}

Danang City is located on the southern Central Coast of Vietnam covering approximately 1,255 square kilometers with a population of 890,500 residents. According to the Vietnam General Statistics Office, Danang City is one of five municipalities that are administratively equivalent to provinces and directly under the central government similar to Hanoi, HoChiMinh City, Haiphong, and Cantho city. Danang City is the fourth most populated city and is one of three major port cities. Its urban growth rate was 3.5\% with the highest urbanization ratio (87\%) among Vietnam's cities and provinces [22]. Danang City GDP growth rate averaged 11\% from 2006-2010, 1.5 times the national average. Danang City is also the economic and academic hub of Central Vietnam [23]. Administratively, Danang City is subdivided into districts, which contain either wards or communes. These are further subdivided into hamlets or villages. For convenience, this paper will use "communes" for communes and wards, and "hamlets" for hamlets and villages.

\section{Study design}

This is a cross-sectional survey that uses a stratified multistage cluster sampling technique to identify households 
for inclusion in this study. The Danang People's Committee provided a list containing the Danang City administrative units and household statistics. The 56 communes in Danang City were stratified into urban, mixed urban/rural, and rural as determined by local government officials - the heads of each local Commune Health Clinic. Mixed urban/ rural communes were defined as those that contain rural areas covering $30 \%$ to $50 \%$ of their geographic boundary. Of the 56 communes in Danang City, 66\% are urban, 23\% are rural; and the remaining $10 \%$ are mixed urban/rural.

We carried out a three-stage cluster sampling stratified by urbanization. We also used disproportionate sampling to allow for sufficient between-strata estimation while minimizing cost and maximizing operational efficiency for data collection [24]. The primary sampling units were the 56 wards. The secondary sampling units were hamlets in the selected wards. The last sampling units were households in the selected hamlets. All individuals $\geq 35$ years of age residing in the selected households were invited to participate in the study. In each strata, we randomly selected communes: 3/37 urban, 2/13 rural, 1/6 mixed. Second, we randomly selected 5 hamlets within each chosen commune (30/242 total hamlets). Third, we randomly selected 30 households within each chosen hamlets (900/3241) total households. The University of Washington's Institutional Review Board approved all study procedures. An equivalent division in the Danang Department of Health also reviewed and approved all study protocol. All study participants provided informed consent.

\section{Data collection}

Study trained commune health staff recruited participants from selected households, and made appointments for participants to visit the local commune health center. During the visit, an interviewer-administered survey was completed. The WHO STEPS instrument from the WHO STEPwise Approach to Chronic Disease Risk Factor Surveillance was utilized as the basis for survey [25] which included questions on demographics, tobacco and alcohol use, physical activity, self-reported history of disease, and dietary intake. Six questions on stroke symptoms from the Questionnaire for Verifying Stroke-Free Status (QVSFS) [26] were also included. Questions on chest pain were from the Rose Angina Questionnaire [27]. These questions were further supplemented by questions on physical function, anxiety and stress taken from other validated instruments.

The clinical assessment included a series of three resting systolic and diastolic blood pressure $(\mathrm{mmHg})$ and heart rate (beats/minute) measured using a digital blood pressure device (Microlife USA, Inc., Clearwater, FL). Participants were asked to sit and relax for 5 minutes prior to blood pressure measurement. Weight ( \pm 0.2 pounds) and percent body fat $( \pm 0.1 \%)$ were measured using the
OMRON Model HBF-400 scale (Omron Corporation, Kyoto, Japan). Height was measured using a standard measuring tape and a head level. Participants were asked to remove their shoes, hat, belt, and pocket items before weight and height measurements were conducted. Spirometry was repeated three times using a Microlife, PF100 digital peak flow meter (Microlife USA, Inc., Clearwater, FL, USA) to obtain forced expiratory volume (FEV) and peak expiratory volume (PEV). Balance and gait were carried out using components in the Short Physical Performance Battery [28].

Two health care workers stationed at each commune health clinic collected the data. Centralized training for data collectors was held to review study procedures, make final modifications, pre-test forms and survey instruments, and conduct field exercises of study procedures. Data were collected between July and December 2010. Study physicians visited the study sites periodically throughout the study period to monitor quality and assure standardization of procedures.

\section{Statistical analysis}

BMI was calculated and categorized using (1) the WHO "standard" cut-offs, as follows: underweight $\left(<18.5 \mathrm{~kg} / \mathrm{m}^{2}\right)$, overweight $\left(25-29.99 \mathrm{~kg} / \mathrm{m}^{2}\right)$ and obese $\left(\geq 30 \mathrm{~kg} / \mathrm{m}^{2}\right)$, and (2) the Asian-specific cut-offs: underweight $\left(<18.5 \mathrm{~kg} / \mathrm{m}^{2}\right)$; overweight $\left(23-27.49 \mathrm{~kg} / \mathrm{m}^{2}\right)$; and obese $\left(\geq 27.5 \mathrm{~kg} / \mathrm{m}^{2}\right)$ [8]. Based on the administrative lists, we calculated sampling weights for each stage of clusters sampled, and subsequently assigned a final sampling weight as the product of weights at each stage. Using statistical survey methods to re-weight our sample back to the population [29], we calculated the prevalence of underweight and overweight/obesity status using two BMI definitions. We conducted separate univariate analyses to assess factors associated with being overweight and underweight/obese. We conducted our analyses for standard WHO cutoffs and repeated for cut-offs suggested for Asian populations. In univariate analyses for categorical variables, we conducted Pearson chi-squared tests corrected for survey design with the second-order of Rao and Scott [30], and converted the test into a design-based F statistic. To test the difference in means of continuous variables across body weight categories, we used generalized linear regression to obtain the Wald test adjusted for the clustered survey design [31]. To test for linear trend of ordered categories, we modeled the ordered categories as one continuous exposure variable and conducted an adjusted Wald test. We conducted multivariate analyses to identify independent factors associated with being underweight and being overweight/obese in separate models. Because neither underweight nor overweight/obese status were rare events in our sample (i.e., > 10\%) and because odds ratios provide biased estimates of prevalence ratios when outcomes are common [32], we used 
generalized linear models instead of logistic regression to obtain prevalence ratios associated with risk factors and demographic and clinical characteristics [33]. We assumed Poisson distribution for the variance to fit our models. All multivariate analyses accounted for the multistage cluster design using survey estimation methods in Stata 11.2 (College Station, TX). We identified independent factors associated with underweight and overweight/obesity status in regression models using a backward stepwise approach. All factors that were significantly associated with BMI categories in univariate analyses were placed into the full model and removed sequentially if corresponding P-value of the adjusted Wald test exceeded 0.05 . Variables selected for potential inclusion in the model were age, gender, income, education, urbanization, smoking status, number of drinks/week consumed, number of days eating fruits/vegetables per week, measured systolic and diastolic blood pressure (per $10 \mathrm{~mm} / \mathrm{Hg}$ ), low physical activity (defined by WHO STEPS survey), self-reported history of stroke, number of stroke symptoms, diabetes, high cholesterol, severe chest pain lasting 30 minutes or longer, cancer, forced expiratory volume, peak flow, and timed walk. Factors that were significantly and independently associated with each outcome were retained in the final models. Because the WHO also suggests Asian-specific BMI cut-offs for "potential public health action points", we repeated our analyses using the suggested cut-offs: < $18.5 \mathrm{~kg} / \mathrm{m}^{2}, 18.5-22.99 \mathrm{~kg} / \mathrm{m}^{2}$, and $\geq 23 \mathrm{~kg} / \mathrm{m}^{2}$ for underweight, normal, and combined overweight/obese, respectively. All tests were two-sided and statistical significance was defined as P-value $<0.05$. Analyses were performed in Stata version 11.2 (College Station, TX).

\section{Results}

Of the 1,713 adults approached for inclusion in the study, 92 from 17 households declined participation resulting in a response rate of $94.5 \%$. A total of 1,621 adults from 887 households provided informed consent and completed the study. Age of participants ranged from 35 to 93 years with a mean of 52.0 years $( \pm 12.5)$; $43.9 \%$ were men. The majority $(64.1 \%)$ were age 35 to $<45$, and $6.7 \%$ were $>75$ years of age (Table 1$)$. The most commonly self-reported condition was tooth pain (31.2\%) followed by joint pain (23.1\%), gum pain (14.1\%), and hypertension (14.1\%). Of note, measured hypertension (SBP>140 or DBP $>90)$ showed nearly twice (27.7\%) the prevalence of self-reported hypertension. Over $25 \%$ of participants were current smokers and another $14.4 \%$ were former smokers, almost all of whom were men. The overall prevalence for underweight and overweight/obesity was $12.4 \%$ and $16.0 \%$, respectively, using the WHO standard cutoff of BMI $\geq 25 \mathrm{~kg} / \mathrm{m}^{2}$. When we applied the suggested Asian-specific overweight/ obesity cutoff of BMI $\geq 23 \mathrm{~kg} / / \mathrm{m}^{2}$, the prevalence doubled (33.8\%). Patterns in prevalence of weight status were evident across communes with varying degrees of urbanization. Prevalence of underweight status rose from $7.4 \%$ to $13.4 \%$ to $20.5 \%$ across urban, mixed urban/rural, and rural communes, respectively - that is, the prevalence increased with decreasing degree of urbanization ( $\mathrm{p}<0.014$, test for trend). Regardless of which BMI cutoffs were used to define overweight and obesity, prevalence lowered significantly with decreasing levels of urbanization (Figure 1). The highest prevalence of overweight status occurred in urban communes for both definitions of overweight/obese status, reaching $43.2 \%$ with Asian-specific BMI $\geq 23 \mathrm{~kg} / \mathrm{m}^{2}$, Figure 2. The prevalence of underweight status generally rose with older age. For either WHO standard and Asian-specific BMI definitions, no linear trends in the prevalence of overweight/obesity were evident according to age; however, the prevalence appeared the highest among 55 to 64 year olds, and lowest among those $75+$ years (Figure 2).

When stratified according to mutually exclusive groups of WHO standard body weight status for underweight, normal, and overweight/obese, we observed univariate associations $(\mathrm{p}<0.05)$ with age, urbanization, household income, self-reported history of hypertension, diabetes and high cholesterol, measured systolic and diastolic blood pressure, measured hypertension, and FEV (Table 1). Associations were not observed for sex, education, or smoking. Similar factors were significantly associated with weight status when we used the Asian-specific cut-offs except for education, which became statistically significant.

In our multivariate models, factors that were independently associated with higher prevalence of underweight status included older age, less urbanization, current smoking status, and lower systolic blood pressure (Table 2). Older age was associated with a higher prevalence of underweight status with the oldest residents ( $75+$ years) having nearly 3 -fold higher prevalence than those younger than 55 years of age. Current smokers had the highest prevalence of being underweight relative to never-smokers, with a significant increasing trend evident across the categories for non-smokers, former smokers, and current smokers $(p=0.028)$. Finally, lower systolic pressure was associated with higher prevalence of being underweight with each $10 \mathrm{mmHg}$ increase associated with a $12 \%$ lower prevalence of being underweight after adjusting for all other factors.

Independent factors associated with being overweight/ obese by standard WHO and Asian-specific BMI definitions are presented in Table 2 . Older age was significantly associated with a lower prevalence of being overweight/ obese by the Asian-specific definition but not by the WHO standard definition. Those from rural communes were less likely to be overweight/obese by both definitions. 
Table 1 Prevalence of Body Weight Status According to Demographic, Reported History, and Measured Variables Among Residents 35 to 93 Years in Danang City, Vietnam, 2010

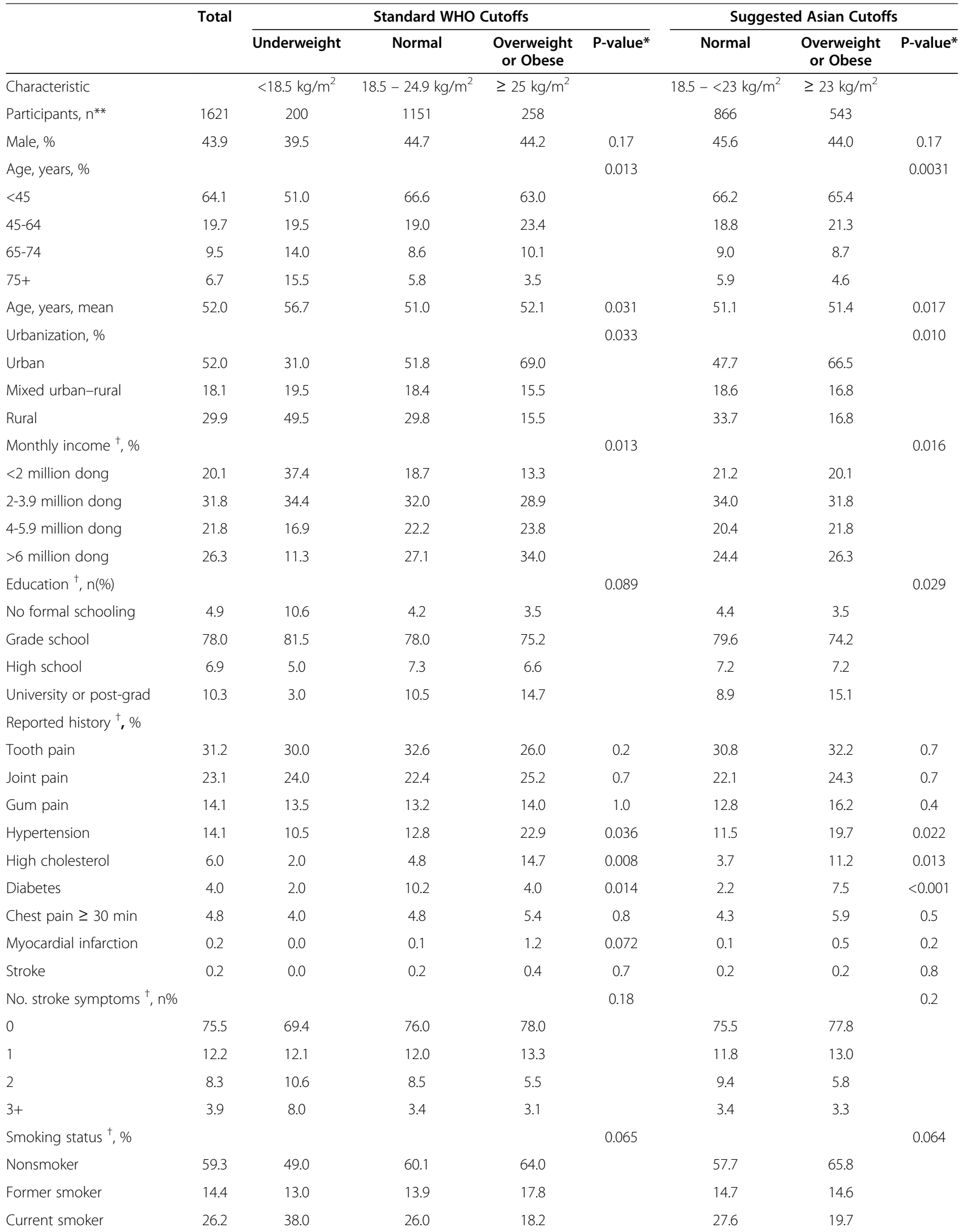


Table 1 Prevalence of Body Weight Status According to Demographic, Reported History, and Measured Variables Among Residents 35 to 93 Years in Danang City, Vietnam, 2010 (Continued)

\begin{tabular}{|c|c|c|c|c|c|c|c|c|}
\hline Drinks per week ${ }^{\dagger}, \%$ & & & & & 0.2 & & & 0.4 \\
\hline None & 65.2 & 71.5 & 64.9 & 61.6 & & 64.2 & 64.5 & \\
\hline$<1 / 2$ & 14.1 & 8.5 & 14.2 & 18.2 & & 14.5 & 15.7 & \\
\hline $1 / 2$ to 2 & 9.4 & 10.5 & 9.1 & 9.7 & & 9.0 & 9.6 & \\
\hline$\geq 3$ & 11.3 & 9.5 & 11.8 & 10.5 & & 12.3 & 10.3 & \\
\hline \multicolumn{9}{|l|}{ Clinical Measurements } \\
\hline Systolic, mmHg, mean & 128.2 & 123.7 & 127.8 & 132.9 & 0.031 & 127.5 & 130.6 & 0.02 \\
\hline Diastolic, mmHg, mean & 80.6 & 77.3 & 80.3 & 84.5 & 0.018 & 80.0 & 82.8 & 0.016 \\
\hline $\begin{array}{l}\text { Hypertension } \\
(\mathrm{SBP} \geq 140 \text { or } \mathrm{DBP} \geq 90)\end{array}$ & 27.7 & 19.5 & 26.9 & 38.0 & 0.047 & 26.3 & 33.0 & 0.004 \\
\hline Fast walk, seconds, mean & 3.6 & 4.1 & 3.6 & 3.4 & 0.4 & 3.6 & 3.4 & 0.4 \\
\hline FEV, L/min, mean & 2.0 & 1.89 & 2.02 & 2.02 & 0.02 & 2.01 & 2.03 & 0.02 \\
\hline PEF, L/min, mean & 2.1 & 2.0 & 2.1 & 2.1 & 0.2 & 2.1 & 2.1 & 0.2 \\
\hline
\end{tabular}

*p-value for design-based $\mathrm{F}$ statistic.

**Population prevalence estimates based on reweighting for these participants in sample.

† Self-reported.

Unlike the model for underweight status, smoking status was not an important independent factor for being overweight/obese by either definition. The associations for systolic blood pressure and diabetes were stronger in the Asian-specific definition. The association between selfreported heart attacks and being overweight/obese was notably strong for the model using the standard WHO cutoff (prevalence ratio $=4.67 ; 95 \% \mathrm{CI} ; 1.37,15.9$ ).

\section{Discussion}

Results of this study provides evidence of the double burden of underweight and overweight/obesity experienced in Danang City, Vietnam. Our 12.3\% overall prevalence of underweight status was similar to the $12.6 \%$ reported by Walls and colleagues [5] for their study conducted in 2004 among provinces surrounding Hanoi, where the population characteristics (i.e. urban, mixed urban-rural, and rural) and economic development were similar to our population. On the other hand, our underweight prevalence was much lower than the $20.4 \%$ for the 2004 urban Ho Chi Minh City (HCMC) cohort [21] and 20.9\% reported by Ha and colleagues for the 2005 Vietnam National Adult Obesity Survey (VNAOS) [19]. The comparision needs to take into consideration that data for all three studies above were collected between 2004-2005 while ours were collected in 2010. The prevalence of underweight status for Vietnam as a whole and for HCMC and Hanoi areas have likely decreased over that time period.

We observed higher prevalences of overweight, 14.9\% and 29.8\%, as defined by WHO standard and Asian-specific definitions, respectively, compared to $6.6 \%$ and $16.3 \%$ for the 2005 VNAOS [19]. However, the prevalences are similar to those reported for the 2004 urban HCMC residents cohort (WHO standard, 15.4\%; Asian-specific, 26.2\%) and for Hanoi and adjacent provinces (WHO standard, 12.2\%, Asian-specific, 27.5\%). The prevalence of being overweight as defined by the WHO standard cut-off in our population and in Vietnam overall remain lower than the $20 \%$ to $30 \%$ reported for many Southeast Asian countries such as Japan, Malaysia, Philippines, Singapore, Thailand, and South Korea with data collected between 1998 and 2004 [34]. Given the trend towards increasing prevalence of overweight/obesity in low- to middle-income countries, particularly those in Asia [7], prevalence estimates of overweight/obesity for the countries noted above have likely risen.

Obesity by WHO standard remained low at $1.1 \%$ for our cohort but increased to $4.0 \%$ when the Asian-specific cut-off was applied. These prevalences are higher than the $0.4 \%$ and $1.7 \%$, respectively, reported for the 2005 VNAOS, which was collected 5 years earlier. Possibly, our prevalence estimates reflect the continuing trend towards decreasing prevalence of underweight status and increasing prevalence of overweight and obesity in Vietnam overall [19]. Furthermore, our population resides in a city that is undergoing higher than national average economic growth; expansion of urban development; growth of urban areas; and shrinkage of rural areas. Urbanization is coupled with greater influences of globalization and increased availability of fatty and high caloric foods and higher food expenditure per capita [35]. Indeed, our obesity prevalences were more closely aligned with those reported for Hanoi City and adjacent provinces $(0.5 \%$, WHO standard; $2.2 \%$, Asian-specific) and HCMC (1.8\%, WHO standard; and 6.4\%, Asian-specific); both regions have economic growth and development similar to if 


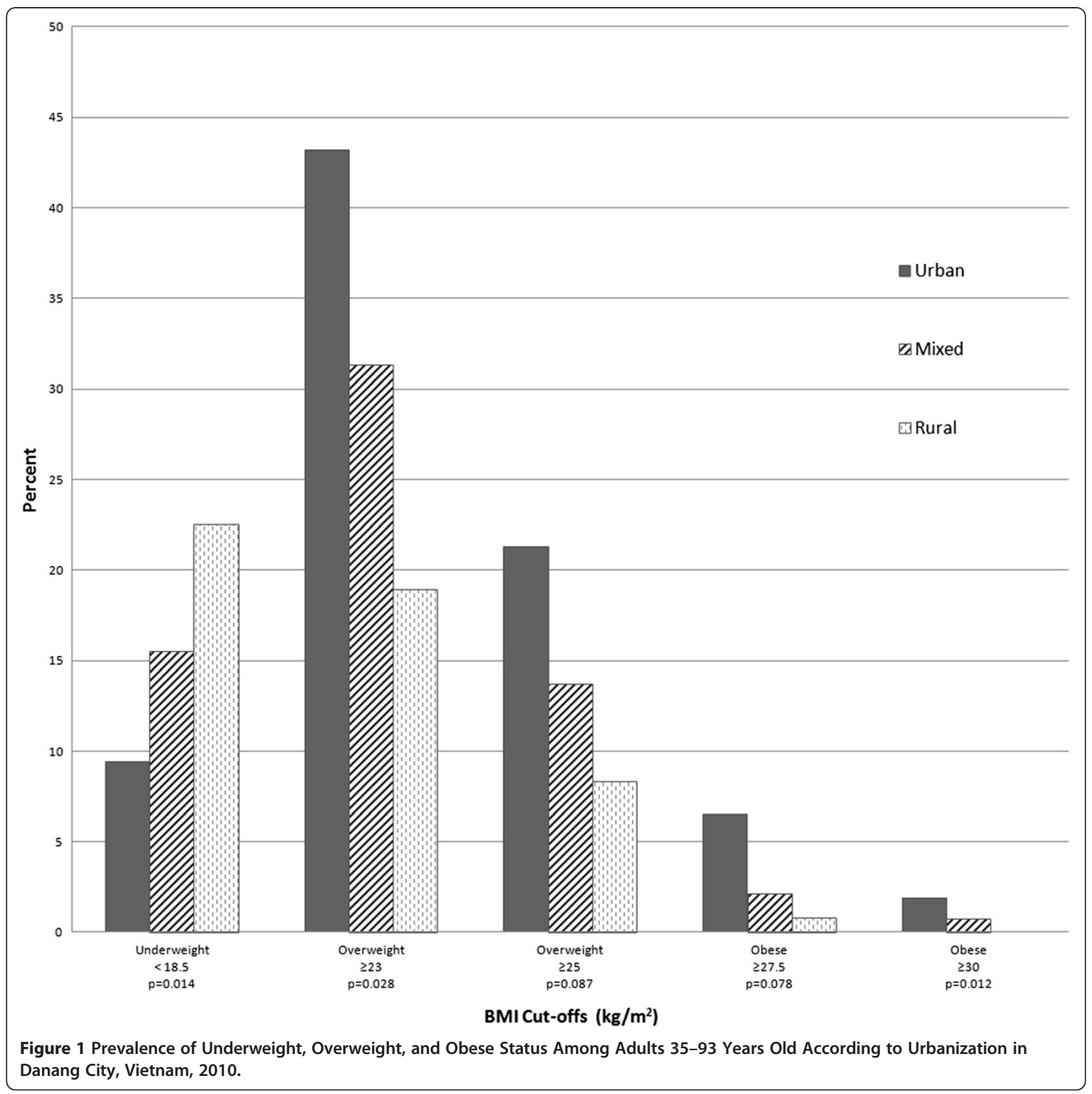

not greater than that in Danang City. Interestingly, HCMC also showed much higher prevalence of underweight status, $20.4 \%$, compared to $12.4 \%$ in Danang and $12.6 \%$ in Hanoi. Perhaps, the situation in HCMC - the economic hub of Vietnam - could be attributed to the increasing disparity in wealth and the existence of urban slums.

Similar to the national study and study conducted in Hanoi, patterns in prevalence of body weight status were evident across communes by urbanization. That is, lower underweight and higher overweight/obesity prevalence were associated with greater urbanization. The highest prevalence of underweight status occurred in rural communes at $23.5 \%$. In the urban communes, $43.3 \%$ had BMI $\geq 23 \mathrm{~kg} / \mathrm{m}^{2}$ while $21.3 \%$ had a BMI $\geq 25 \mathrm{~kg} / \mathrm{m}^{2}$. These trends likely reflect continuing national and regional expansion of urbanization, growth of mixed urban-rural areas and reduction of rural populations.

The prevalence of underweight increased with age for both standard WHO and Asian-specific definitions of overweight/obesity prevalence decrease after age 65 years. These are in agreement with results reported in the 2005 national survey. The trend of having lower BMI at older ages is not unusual, even in western 


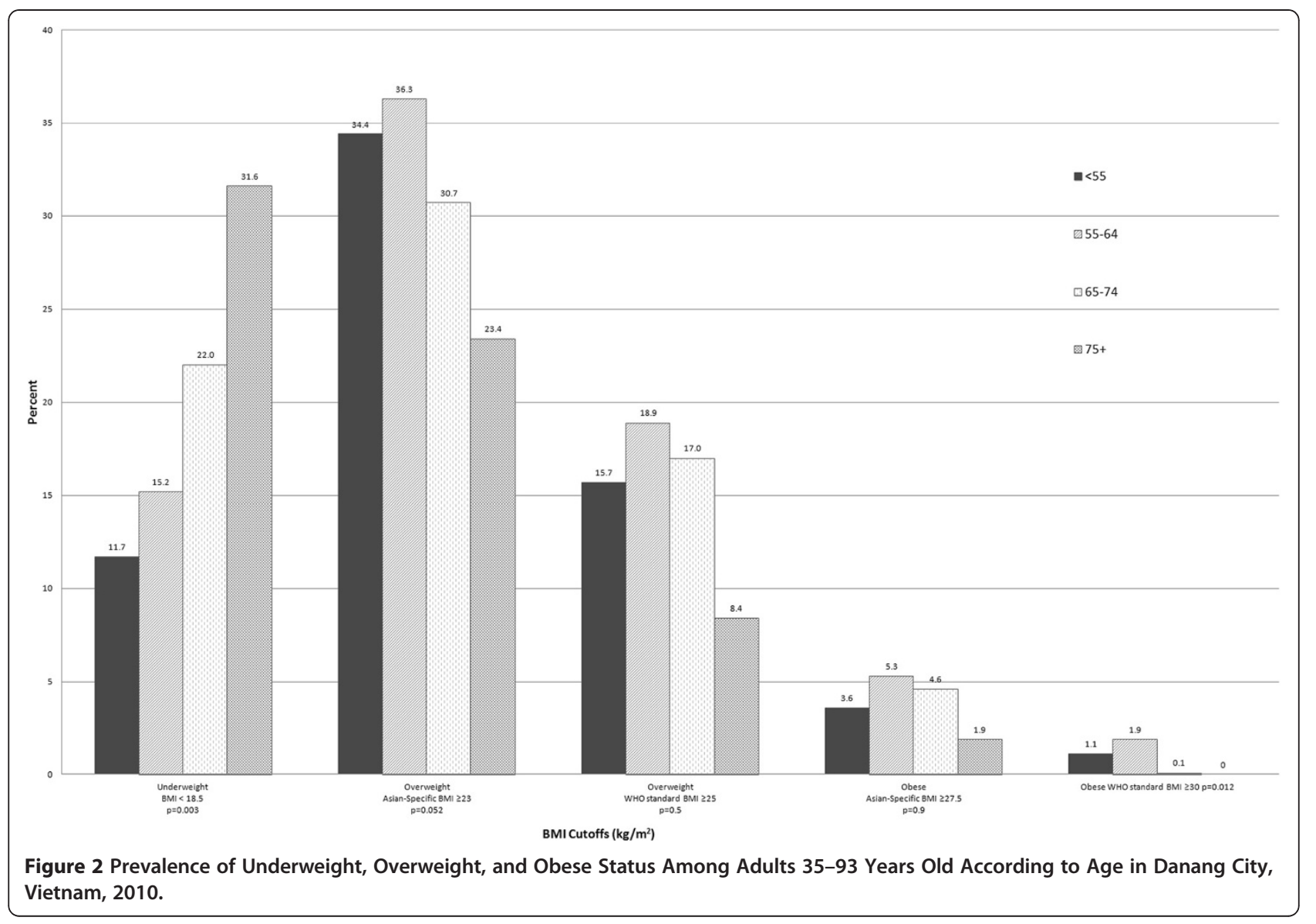

nations, as age is affiliated with physical parameters such as frailty [36], and mental conditions such as dementia [37], that are manifested by weight-loss.

The prevalence of overweight was highest for those 35-64 and peaks between 55-64 years of age. For Asian-specific BMI definition, factors associated with overweight/obesity included age, living in urban communes, increased systolic blood pressure, and diabetes. Age was not an associated factor when using the WHO standard definition; however, a reported history of myocarial infarction became highly significant. While income did not remain in the model, urbanization was highly associated with overweight status suggesting that urban living, which provides greater opportunities to access inexpensive processed foods and foods with high refined carbohydrate content, may be the driving force in the rise of overweight/obesity occuring in Danang City and perhaps throughout urban Vietnam. Similar to results found for underweight status, the association of overweight/obesity with health conditions such as diabetes, systolic hypertension, and heart attacks are likely consequences of increased BMI. Knowledge of these associations may provide stimulus for interventions in Danang City and in Vietnam to address the increasing prevalences of overweight/obesity and their impact on the chronic disease burden evident in many other low- and middle-resource countries .

Overall, our study suggests that important chronic conditions such as diabetes, higher systolic blood pressure, and cardiovascular risk factors are significantly and independently associated with being overweight/obese when defined by WHO standard. With the exception of heart attack, these same factors remain importantly related to being overweight/obese as defined by the Asian-specific definition. Although it remains unclear which cut-off points are appropriate for which Asian ethnic groups, what is clear is the need to consider alternative BMI definitions of overweight and obesity as a number of important chronic diseases risk factors appear to remain important at BMI cut-offs lower than the WHO standard definition. Noncommunicable diseases such as heart disease, diabetes and cancer are now the leading causes of death in low- to middle-income countries. The WHO reports that noncommunicable diseases make up the highest proportion of deaths among both men and women in low- and middleincome countries. Twenty-nine percent of these deaths occur in people under the age of 60 in these countries compared to $13 \%$ in high-income countries [38]. 
Table 2 Independent Factors Associated with Underweight and Overweight Status Among Residents 35 - 93 Years of Age: Danang Province, Vietnam, 2010

\begin{tabular}{|c|c|c|c|c|c|c|c|c|c|}
\hline & Unde & weight $<18$ & & Overwe & ht as $\mathrm{BMI} \geq$ & & Overw & ight as BMI & 25 \\
\hline & $\begin{array}{c}\text { Prevalence } \\
\text { Ratio }\end{array}$ & $95 \% \mathrm{Cl}$ & $\overline{p \text {-value }}$ & $\begin{array}{c}\text { Prevalence } \\
\text { Ratio }\end{array}$ & $95 \% \mathrm{Cl}$ & & $\begin{array}{c}\text { Prevalence } \\
\text { Ratio }\end{array}$ & $95 \% \mathrm{Cl}$ & $p$-value \\
\hline$\overline{\mathrm{Age}^{\ddagger}}$ & & & 0.001 & & & 0.047 & & & \\
\hline$<45$ & 1.00 & Reference & & 1.00 & Reference & & - & - & \\
\hline $45-64$ & 1.47 & $(0.88,2.47)$ & & 0.96 & $(0.78,1.19)$ & & - & - & \\
\hline $65-74$ & 2.11 & $(1.47,3.03)$ & & 0.87 & $(0.60,1.28)$ & & - & - & \\
\hline $75+$ & 2.76 & $(2.26,3.38)$ & & 0.79 & $(0.62,1.00)$ & & - & - & \\
\hline Urbanization & & & 0.029 & & & 0.045 & & & 0.13 \\
\hline Urban & 1.00 & Reference & & 1.00 & Reference & & 1.00 & Reference & \\
\hline Mixed urban-rural & 1.55 & $(0.91,2.64)$ & & 0.78 & $(0.60,1.01)$ & & 0.71 & $(0.50,1.00)$ & \\
\hline Rural & 2.12 & $(0.98,3.47)$ & & 0.52 & $(0.27,1.00)$ & & 0.47 & $(0.13,1.74)$ & \\
\hline Smoking Status ${ }^{\ddagger}$ & & & 0.028 & & & & & & \\
\hline Never & 1.00 & Reference & & - & - & & - & - & \\
\hline Former & 1.11 & $(0.41,2.41)$ & & - & - & & - & - & \\
\hline Current & 1.80 & (1.13 2.16) & & - & - & & - & - & \\
\hline Systolic pressure $(10 \mathrm{mmHg})$ & 0.88 & $(0.77,0.99)$ & & 1.06 & $(1.03,1.12)$ & & 1.11 & $(1.00,3.72)$ & \\
\hline Diabetes $^{\dagger}$ & - & - & & 1.60 & $(1.37,1.86)$ & & 2.12 & $(1.20,1.45)$ & \\
\hline Heart attack ${ }^{\dagger}$ & - & - & & - & - & & 4.67 & $(1.37,15.9)$ & \\
\hline
\end{tabular}

*underweight defined as $\mathrm{BMl}<18.5$; reference group defined as normal BMI (18.5-24.9); 258 subjects overweight $(\geq 25)$ were excluded from analyses.

${ }^{\dagger}$ Adjusted for all other factors in table.

Several limitations exist in our study. The cross-sectional design precludes the ability to discern temporality, although it is reasonable to suggest that lifestyles may precede diseases and diseases may result from weight status, an indicator of nutritional status. Second, besides blood pressure, which was objectively measured as part of the study, medical conditions such as arthritis, myocardial infarction, hypercholesterolemia were self-reported. Precise knowledge of personal medical history depends on health care utilization behaviors and interest in one's own health that are likely to vary according to history with the health care system, education, income, and geographical location of residence. Third, our sample was restricted to participants 35 years and older; therefore, our results are not generalizable to those younger than 35 years of age.

\section{Conclusions}

These results present evidence of the double burden of underweight and overweight/obesity in Danang City, consistent with the patterns found in other large cities in Vietnam that are undergoing similar rapid economic growth, urbanization, and westernization of lifestyle. Prevalence of overweight/obesity significantly increased when using Asian-specific BMI. Factors independently associated with underweight and overweight/obesity status by both WHO standard and Asian-specific definition include age, urbanization, and some modifiable lifestyle behaviors. Further studies are needed to help define ethnic specific BMI cut-offs for Vietnam and to explore strategies to reduce the rising prevalence of overweight and obesity.

\section{Abbreviations}

BMI: Body Mass Index; FEV: Forced Expiratory Volume; HCMC: Ho Chi Minh City; VNAOS: Vietnam National Adult Obesity Survey; WHO: World Health Organization.

\section{Competing interests}

The authors declare that they have no competing interests or non-financial competing interests.

\section{Author's contributions}

ALF was the principle investigator of the main research project and was primarily responsible for the administration and conduct of the study. She led the team in formulating the research questions and producing the survey instrument. She provided training to field workers and in epidemiology and research method to the local researchers. KAL was the project coordinator and primary liaison with the local research team. QVN was the local project coordinator. KAL and QVN participated in formulating the research questions, in producing and translating the survey instrument, and in training field workers. They served as conduits with local authorities regarding study design and procedures. They implemented and supervised the study conduct and visited field sites. TTV developed and managed the study database. TTV and QVN double-entered and checked data for quality control. TGNT provided methodological expertise and conducted data cleaning and data analyses. She also provided training to field workers and in epidemiology and data management to the local researchers. KAL was the primary author of this manuscript. TGNT assisted in writing the manuscript. ALF, QVN, and TTV provided critical revision of the manuscript for intellectual content. All authors read and approved the final manuscript.

\section{Acknowledgements}

This research was supported by grant R21-TW008431 from the Fogarty International Center (FIC) and the National Institute of Neurological Disorders and Stroke (NINDS) of the National Institute of Health, USA. The authors 
would like to thank the Danang Department of Health, the Danang Hospital, the Danang People's committee, and the local Advisory Committee for their support and guidance of the project and for allotting time for QVN, TTV, and other staff to actively participate in the project. The authors also would like to thank the outstanding field workers at the hamlet Community Health Centers for their tireless efforts in contacting participants, carrying out the study procedures and collecting quality data. Finally, the authors owe much gratitude to Dr. Chien H. Pham, Director of the Danang Department of Health and Dr. Hieu Q. Tran, Vice Director of Danang Hospital, for their unwavering support and guidance.

\section{Author details}

'Department of Oral Health Sciences, School of Dentistry, University of Washington, Seattle, WA, USA. ${ }^{2}$ Department of Neurology, School of Medicine, University of Washington, Seattle, WA, USA. ${ }^{3}$ Department of Health, Danang, Vietnam. ${ }^{4}$ Departments of Epidemiology \& of Global Health, University of Washington, Seattle, WA, USA.

Received: 29 March 2012 Accepted: 11 January 2013

Published: 14 January 2013

\section{References}

1. Burton BT, Foster WR, Hirsch J, Van Itallie TB: Health implications of obesity: an NIH consensus development conference. Int J Obes 1985, 9(3):155-170.

2. Must A, Spadano J, Coakley EH, Field AE, Colditz G, Dietz WH: The disease burden associated with overweight and obesity. JAMA 1999, 282 (16):1523-1529.

3. Gillespie S, Haddad LJ: Attacking the double burden of malnutrition in asia and the pacific. Manila: asian development bank. Washington D C: International Food Policy Research Institute; 2001. Available: http://pdf.usaid. gov/pdf_docs/PNACN866.pdf (accessed 2012 Dec. 19).

4. Gillespie S, Haddad L: The double burden of malnutrition in Asia: causes, consequences, and solutions. New Delhi: Thousand Oaks: Sage Publications; 2003.

5. Walls HL, Peeters A, Son PT, Quang NN, Hoai NT, Loi do D, Viet NL, Khai PG, Reid CM: Prevalence of underweight, overweight and obesity in urban Hanoi, Vietnam. Asia Pac J Clin Nutr 2009, 18(2):234-239.

6. Food and Agriculture Organization of the United Nations: The double burden of malnutrition: case studies from six developing countries. Rome: Food and Agriculture Organization of the United Nations; 2006. Available: ftp://ftp.fao. org/docrep/fao/009/a0442e/a0442e00.pdf (accessed 2012 Dec. 15).

7. Popkin BM, Adair LS, Ng SW: Global nutrition transition and the pandemic of obesity in developing countries. Nutr Rev 2012, 70(1):3-21.

8. Ke-You G, Da-Wei F: The magnitude and trends of under- and overnutrition in Asian countries. Biomed Environ Sci 2001, 14(1-2):53-60.

9. WHO: Obesity: preventing and managing the global epidemic. Report of a WHO consultation. World Health Organ Tech Rep Ser 2000, 894(i-xii):1-253.

10. Low S, Chin MC, Ma S, Heng D, Deurenberg-Yap M: Rationale for redefining obesity in Asians. Ann Acad Med Singapore 2009, 38(1):66-69.

11. Deurenberg $P$, Deurenberg-Yap M, Guricci $S$ : Asians are different from Caucasians and from each other in their body mass index/body fat percent relationship. Obes Rev 2002, 3(3):141-146.

12. Cameron AJ, Sicree RA, Zimmet PZ, Alberti KG, Tonkin AM, Balkau B, Tuomilehto J, Chitson P, Shaw JE: Cut-points for waist circumference in europids and south Asians. Obesity (Silver Spring) 2009, 18(10):2039-2046,

13. Foucan L, Hanley J, Deloumeaux J, Suissa S: Body mass index (BMI) and waist circumference (WC) as screening tools for cardiovascular risk factors in guadeloupean women. J Clin Epidemiol 2002, 55(10):990-996.

14. Lin WY, Lee LT, Chen CY, Lo H, Hsia HH, Liu IL, Lin RS, Shau WY, Huang KC: Optimal cut-off values for obesity: using simple anthropometric indices to predict cardiovascular risk factors in Taiwan. Int J Obes Relat Metab Disord 2002, 26(9):1232-1238.

15. Ko GT, Chan JC, Cockram CS, Woo J: Prediction of hypertension, diabetes, dyslipidaemia or albuminuria using simple anthropometric indexes in Hong Kong Chinese. Int J Obes Relat Metab Disord 1999, 23(11):1136-1142.

16. Nishimura R, Nakagami T, Tominaga M, Yoshiike N, Tajima N: Prevalence of metabolic syndrome and optimal waist circumference cut-off values in Japan. Diabetes Res Clin Pract 2007, 78(1):77-84.

17. Aekplakorn W, Kosulwat V, Suriyawongpaisal P: Obesity indices and cardiovascular risk factors in Thai adults. Int J Obes (Lond) 2006, 30(12):1782-1790.
18. WHO EC: Appropriate body-mass index for Asian populations and its implications for policy and intervention strategies. Lancet 2004, 363 (9403):157-163.

19. Ha DTP, Feskens EJ, Deurenberg P, Le MB, Khan NC, Kok FJ: Nationwide shifts in the double burden of overweight and underweight in Vietnamese adults in 2000 and 2005: two national nutrition surveys. BMC Publ Health 2011, 11:62.

20. Khan NC, Khoi HH: Double burden of malnutrition: the Vietnamese perspective. Asia Pac J Clin Nutr 2008, 17(Suppl 1):116-118.

21. Cuong TQ, Dibley MJ, Bowe S, Hanh TT, Loan TT: Obesity in adults: an emerging problem in urban areas of Ho Chi minh city, Vietnam. Eur J Clin Nutr 2007, 61(5):673-681.

22. Vietnam General Statistics Office: The 2009 Vietnam population and housing census- migration and urbanization in Vietnam: patterns, trends and differentials; Available: http://www.gso.gov.vn/default_en.aspx? tabid=515\&idmid=5\&ltemlD=11121 (accessed 2012 Dec. 15).

23. Danang People's Committee: Danang investment promotion center. Strong and sustained GDP growth. Available: http://investdanang.gov.vn/modules/ news/default.aspx?Cateld=News_Investment_Enviroment\&Newsld=168 (accessed 2012 Dec. 15).

24. Daniel J: Sampling essentials: practical guidelines for making sampling choices. 11th edition. Los Angeles: Sage Publications; 2011.

25. WHO: The WHO STEP wise approach to chronic disease risk surveillance. Saudi Med J 2003, 24(10):1154-1156.

26. Jones WJ, Williams LS, Meschia JF: Validating the questionnaire for verifying stroke-free status (QVSFS) by neurological history and examination. Stroke 2001, 32(10):2232-2236.

27. Rose GA, Ahmeteli M, Checcacci L, Fidanza F, Glazunov I, De Haas J, Horstmann P, Kornitzer MD, Meloni C, Menotti A, et al: Ischaemic heart disease in middle-aged men. Prevalence comparisons in Europe. Bull World Health Organ 1968, 38(6):885-895.

28. Guralnik JM, Simonsick EM, Ferrucci L, Glynn RJ, Berkman LF, Blazer DG, Scherr PA, Wallace RB: A short physical performance battery assessing lower extremity function: association with self-reported disability and prediction of mortality and nursing home admission. J Gerontol 1994, 49(2):M85-M94.

29. Stata Corporation: Stata statistical software release 11. TX: Stata Corp: College Station; 2011.

30. Rao JNK, Scott AJ: On chi-squared tests for multi way contingency tables with cell proportions estimated from survey data. Ann Stat 1984, 12:46-60.

31. Stata Corporation: Stata reference manual: release 6. TX: Stata Corp: College Station; 1999.

32. Rothman KJ, Greenland S, Lash TL: Modern epidemiology. 3rd edition Philadelphia: Wolters Kluwer Health/Lippincott Williams \& Wilkins; 2008.

33. Lumley T, Kronmal R, Ma S: Relative risk regression in medical research: models, contrasts, estimators, and algorithms. UW Biostatistics Working Paper Series 2006, Working Paper 293:1787.

34. Asia Pacific Cohort Studies Collaboration: The burden of overweight and obesity in the Asia-pacific region. Obes Rev 2007, 8(3):191-196.

35. Food and Agriculture Organization of the United Nations: Globalization of food systems in developing countries: impact on food security and nutrition. Rome: Food and Agriculture Organization of the United Nations; 2004. Available: http://www.fao.org/docrep/007/y5736e/y5736e00.htm (accessed 2012 Dec. 15)

36. Heuberger RA: The frailty syndrome: a comprehensive review. J Nutr Gerontol Geriatr 2011, 30(4):315-368.

37. Soto ME, Secher M, Gillette-Guyonnet S, Abellan van Kan G, Andrieu S, Nourhashemi F, Rolland Y, Vellas B: Weight loss and rapid cognitive decline in community-dwelling patients with Alzheimer's disease. J Alzheimers Dis 2011, 28(3):647-654.

38. WHO: Global status report on non communicable diseases 2010, description of the global burden of NCDs, their risk factors and determinants. Geneva, Switzerland: World Health Organization; 2011. Available: http://whqlibdoc. who.int/publications/2011/9789240686458_eng.pdf (accessed 2012 Dec. 15).

doi:10.1186/1471-2458-13-35

Cite this article as: Ly et al:: Double burden: a cross-sectional survey assessing factors associated with underweight and overweight status in Danang, Vietnam. BMC Public Health 2013 13:35. 